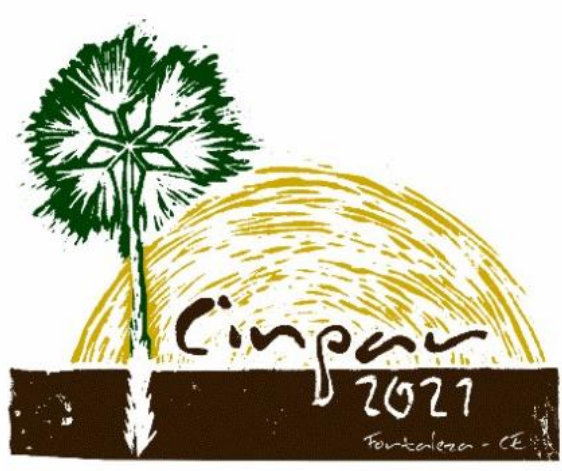

XVII Congresso Internacional sobre Patologia e Reabilitação das Construções

XVII Congreso Internacional sobre Patología y Rehabilitación de las Construcciones

XVII International Conference on Pathology and Constructions Rehabilitation

FORTALEZA (Brasil), 3 a 5 de junho de 2021

https://doi.org/10.4322/CINPAR.2021.160

\title{
Manifestações Patológicas nos Produtos Cerâmicos Utilizados nas Obras de Construção Civil
}

\section{Pathological Manifestations in Ceramic Products Used in Civil Construction Works}

\author{
Juscelino Chaves SALES ${ }^{1}$ \\ ${ }^{1}$ Universidade Estadual Vale do Acaraú, Sobral, Brasil, juscelinochaves@hotmail.com ${ }^{1}$
}

\begin{abstract}
Resumo
As construções estão sujeitas as adversidades dos meios naturais o que pode acarretar a destruição das obras de engenharia. Os materiais cerâmicos principalmente os de cerâmica vermelha, como tijolos, telhas etc. são um dos mais antigos utilizado pelo homem na construção das edificações. O presente trabalho faz uma análise das diversas manifestações patológicas que ocorreram em algumas edificações, nos produtos cerâmicos, com mais ênfase aos produtos cerâmicos produzidos pela indústria de cerâmica vermelha como as telhas, blocos de vedação, tijolos maciços, ladrilhos etc. $O$ principal objetivo desse trabalho foi saber o porquê do aparecimento dessas manifestações patológicas, como também mostrar cada manifestação patológica ocorrida em algumas edificações em duas cidades do estado do Ceará. Foi possível concluir que as manifestações patológicas nos produtos cerâmicos acontecem devido a constituição da argila onde se constatou que quando a argila para se fabricar os blocos cerâmicos possui sal ( $\mathrm{NaCl})$ e se deterioram depois de um certo tempo da sinterização (queima) do tijolos o que vai ocorrer nas obras de engenharia e também foi possível encontrar eflorescência em ladrilhos de cerâmica vermelha e em telhas cerâmicas, como também o envelhecimento das telhas cerâmicas que estão sujeitas ao sol e chuva durante a sua vida util. Através de visitas feitas in loco as edificações, foi possível perceber, que as manifestações patológicas encontradas como a eflorescência, o envelhecimento etc., decorem do material utilizado (argila), do ambiente em que eles estão e dentre outros fatores, como a umidade e o ataque de ácidos. Faz-se necessário fazer uma profilaxia nos produtos cerâmicos para que as manifestações patológicas não venham a ocorrer novamente.

Palavras-chave: manifestações patológicas, produtos cerâmicos, eflorescência.
\end{abstract}

\section{Introdução}

Nas edificações faz-se necessário a utilização de materiais que tenham durabilidade, ou seja, sejam menos susceptíveis as manifestações patológicas e de baixo custo. Dentre esses materiais podemos citar os materiais cerâmicos da indústria de cerâmica vermelha como os tijolos para vedação, blocos para alvenaria estrutural, telhas, lajotas etc. Os materiais cerâmicos da indústria de cerâmica vermelha utilizados na indústria da construção civil apresentam uma grande relevância e vêm evoluindo ao longo dos séculos.

A busca constante pela qualidade nos setores da construção civil faz com que estudos acerca das patologias sejam realizados para que as causas de ocorrência das mesmas sejam identificadas e corrigidas, e principalmente, para que sejam elaborados procedimentos que evitem seu surgimento, já que representam gastos com reformas não previstas, atraso no cronograma de obra (Frazão, 2015). 
Para que as edificações terem uma longa vida útil, citando om exemplo da Catedral de Notre Dame em Paris na França, que já tem mais de 860 anos de vida útil é necessário que se faça um excelente projeto da obra com um planejamento perfeito, a utilização dos melhores materiais, a execução bem-feita da obra, como também a manutenção bem-feita seguindo o que prescreve todas as normas técnicas de engenharia existente. A Catedral de Notre Dame foi construída utilizando o sistema construtivo de alvenaria estrutural com blocos maciços cerâmicos fabricados nas antigas olarias (indústrias) de cerâmica vermelha da época, mostrando assim a longa vida útil desses materiais.

Com o setor da construção civil em foco, o grau de importância dada à qualidade dos produtos utilizados e nos serviços prestados aumentou, assim, a satisfação do cliente passou a ser uma condição primordial dentro das organizações. Diretamente ligado a isso, tem-se o surgimento das patologias, com suas causas relacionadas à má qualidade dos produtos empregados, à desqualificação da mão de obra atuante, à falta de realizações periódicas de manutenções, deficiências no planejamento (Frazão, 2015).

Pesquisadores por meio do mapeamento de danos investigaram prioritariamente o estudo de patologias na alvenaria de tijolos cerâmicos à vista na estação Franco da Rocha da primeira ferrovia do Estado de São Paulo, implantada em 1867. Foram encontradas eflorescências presentes abaixo do guichê de bilheteria e fissuras os ladrilhos de cerâmica vermelha. As manisfestações patológicas mais frequentes econtradas nas paredes de alvenaria feitas de tijolos cerâmiocs são a desagregação, o esmagamento e a fendilhação (Secco, 2018).

A vida útil também depende das exigências que a edificação foi submetida, pois podem ocorrer terremotos. furações etc. que são fenômenos atípicos que muitas vezes não estão previstos no projeto e a vão danificar as edificações.

O tijolo tem demostrado seu êxito ao longo dos milênios se adaptando a todos os tipos de construção e sistemas estruturais em todas as épocas, culturas e estilos arquitetônicos. Sua vigência e suas possibilidades estão acima de qualquer dúvida. Porém, quando acontecem falhas no projeto da obra ou deficiências na qualidade dos tijolos, o meio passa a desenvolver patologias e danos que colocam em risco a estabilidade da obra (Gil, 2007).

Entre os Problemas em telhados temos o transbordamento ou penetração de água, entupimento das calhas ou condutores, envelhecimento das telhas e danos causados pela ação do vento são os mais comuns (AECWEB, 2020).

As eflorescências constituem uma patologia frequente nos produtos cerâmicos (cerâmica vermelha) tradicionais, cuja solução é particularmente difícil ou impossível. Evitar a eflorescência esbarra na impossibilidade física de realizar a total eliminação de sais solúveis quando presentes no corpo cerâmico (Ferreira, 2011).

Pesqisadores estudaram a patologia em paredes de alvenaria (tijolos) e mostram as causas e soluções para a manifestações patológicas e constataram que a patologia da construção deve ser sempre encarada como um passo - indesejado mas praticamente inevitável - rumo à qualidade (Silva, 2007).

Entre as anomalias estruturais em tjolos cerâmicos podemos citar as fissurações, esmagamentoes, erosão, desagregações e abaulamentos e entre as anomalias não estruturais eflorecências, empolamentos manchas, perda de tonalidade, bolor, fungos e umidades(de precipitação, ascendente e de condensação) (Flores \& Brito, 2005).

O presente trabalho tem como objetivo analisar as manifestações patológicas em materiais cerâmicos, principalmente os materiais da indústria de cerâmica vermelha como as telhas, blocos cerâmicos (tijolos maciços e tijolos furados), ladrilhos etc. usados pela indústria da construção civil.

\section{Metodologia}

Para a realização deste trabalho foram feitas visitas in loco em algumas edificações onde foram feitas inspeções visuais em edificações de duas cidades do Estado do Ceará para analisar quais as manifestações patológicas existente em produtos da indústria de cerâmica vermelha como as telhas, tijolos (blocos de vedação), ladrilhos cerâmicos principalmente os expostos à vista nas edificações. Durante as visitas foram feitos registros fotográficos e inspeção visual para detectar as manifestações patológicas. Também foi feita 
uma pesquisa de cunho bibliográfico relacionada ao tema proposto em sites, artigos, monografias, apontamentos de disciplina etc.

\section{Manifestações patológicas nos produtos cerâmicos no Estado do Ceará}

A Figura 1 mostra um muro construído com blocos cerâmicos onde o reboco caiu em quase a totalidade da parede. Isto ocorreu devido a deterioração dos blocos cerâmicos cujo fato acontece porque na argila que foi fabricado os blocos existia uma grande quantidade de salitre (sal) e com o passar do tempo a argila que foi queimada para fabricar os tijolos começa a reagir e vai virando um pó (baixa granulometria) avermelhado. Na realidade ocorreu uma desagregação que corresponde à perda de coesão com queda do material sob a forma de pó ou pequenos fragmentos, onde também podemos dizer que houve uma pulverização.

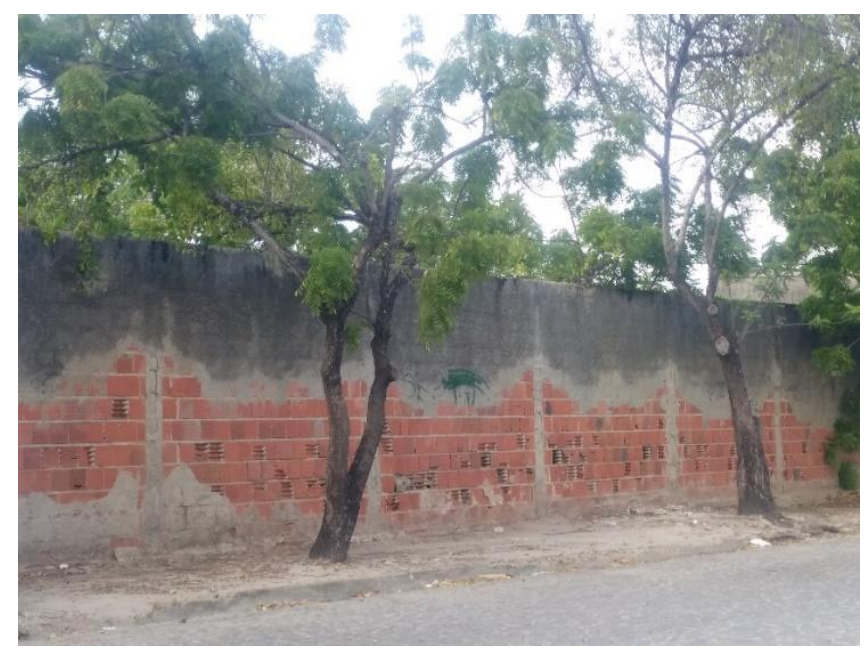

Figura 1 - Muro construído com blocos cerâmicos onde o reboco caiu devido a deterioração dos blocos cerâmicos. Fonte: própia, 2020.

Antigamente os tijolos fabricados de cerâmica vermelha eram todos de blocos maciços, onde foi possível perceber a deterioração dos blocos cerâmicos também devido a existência de salitre na argila, como tínhamos encontrado anteriormente nos blocos (tijolos) de vedação furados. A deterioração dos tijolos (perda de material) acarretou a queda de todo o reboco no local onde ocorreu a manifestação patológica (Figura 2).

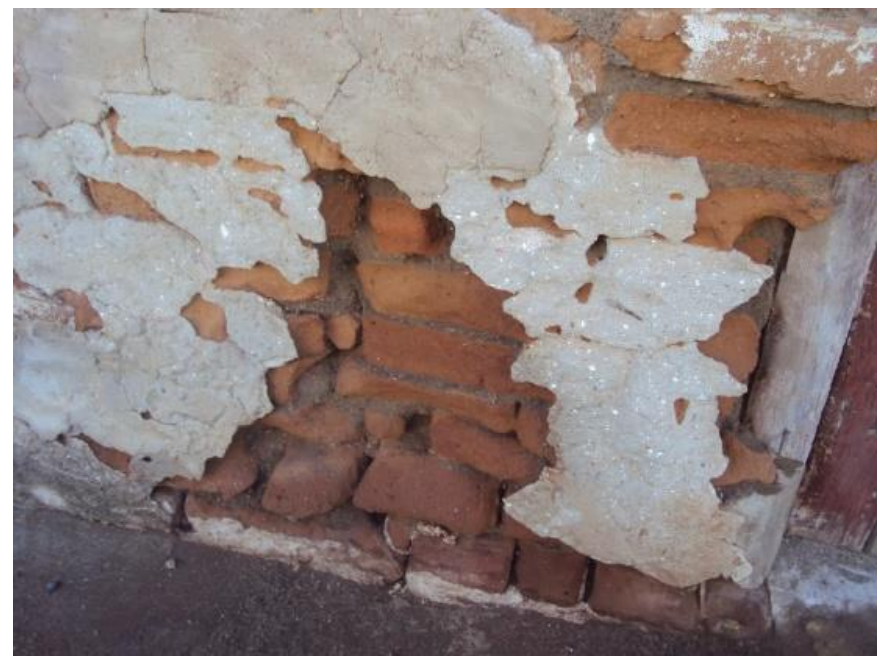

Figura 2 - Deterioração dos blocos cerâmicos devido a existência de salitre na argila. Fonte: própia, 2014. 
Os tijolos, telhas, tubos cerâmicos fabricados de cerâmica vermelha ao longo de sua vida útil sofrem ataques físicos e químicos que incidem também sobre os ladrilhos (cerâmica vermelha) utilizados como revestimentos. A Figura 3 mostra ladrilhos de cerâmica vermelha colocados como revestimento em um pilar, que sofreram ataques de ácidos, ocorrendo assim a deterioração do ladrilho. A edificação foi construída a cerca de 26 anos atrás.

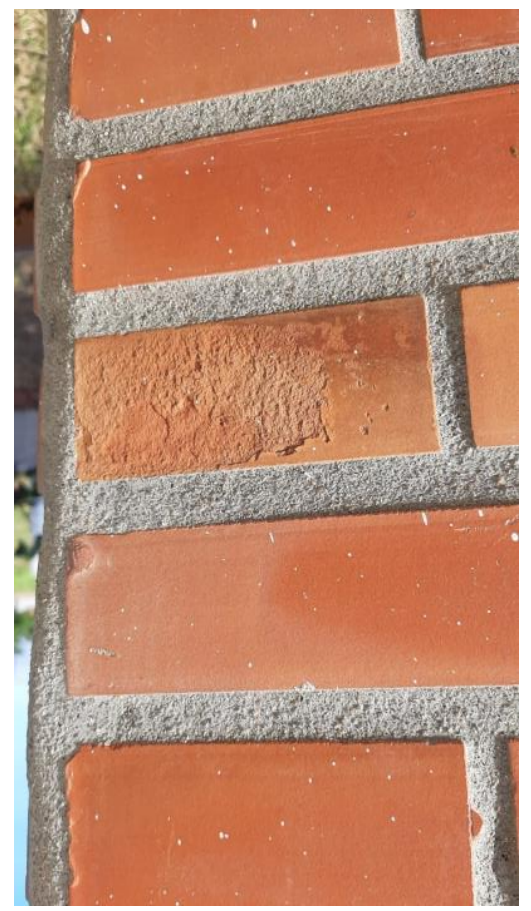

Figura 3 - Ladrilhos de cerâmica vermelha colocados como revestimento em um pilar, que sofreram ataques de ácidos. Fonte: própia, 2021.

É possivel perceber a manifestação patologica eflorecência na parte branca, devido a deposição de sais nos ladrilhos de ceramica vermelha expostos á vista, bem na base de um pilar em uma edificação de mais de 20 anos na cidade de Fortaleza pode sere vista na Figura 4. Também é possivel perceber dois ladrilhos mais escuro que os outros dois devido a existência de umidade no local pois a edificação fica localizada próxima às margens de um riacho e um pequeno açude.

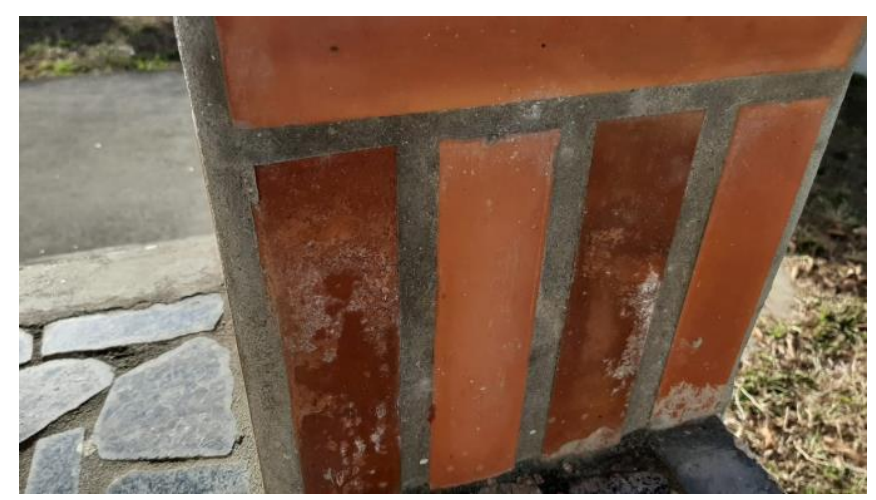

Figura 4 - Manifestações patológicas eflorecência na parte branca e umidade nos ladrilhos expostos á vista. Fonte: própia, 2021.

As ruinas do engenho e a casa José de Alencar no bairro Alagadiço na cidade de Fortaleza foram construídos em tijolos maciços de cerâmica vermelha fabricados manualmente. Foi possível perceber manifestações patológicas como eflorescência e umidade nos tijolos maciços que foram sinterizados (queimados) durante a sua fabricação com temperaturas de sinterização (queima) maiores que $850^{\circ} \mathrm{C}$ (Figura 5). 
As ruinas arqueológicas do antigo engenho e da casa José de Alencar, que foram construídas no ano de 1826 é tombada pelo Instituto do Patrimônio Histórico e Artístico Nacional (IPHAN) (UFC, 2021). Assim foi possível perceber que mesmo com tanto tempo de uso os tijolos cerâmicos maciços expostos a vista, não se degradaram tanto, mostrando que os materiais cerâmicos de cerâmica vermelha resistem mais a incidência de manifestações patológicas no decorrer de sua vida útil em relação a quase todos os materiais utilizados hoje pela indústria da construção civil.

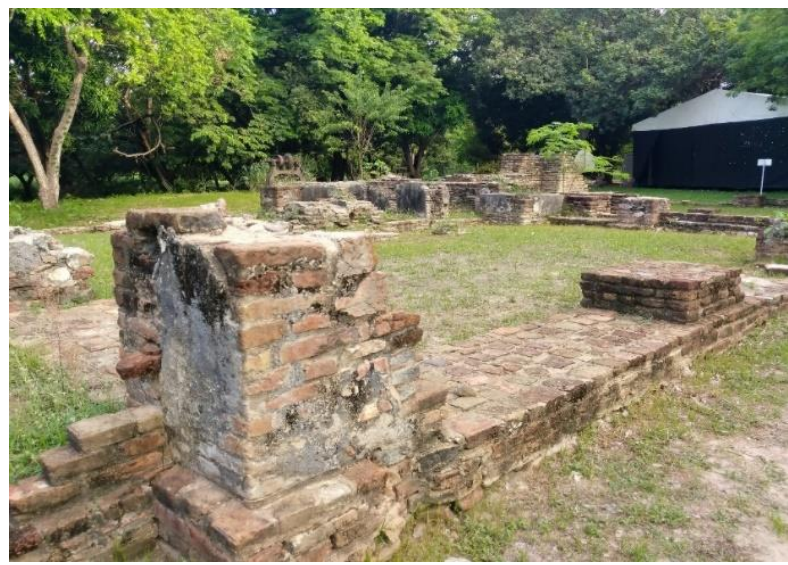

Figura 5 - Manifestações patológicas eflorescência e umidade nos tijolos maciços nas ruinas arqueológicas do engenho. Fonte: própia, 2018.

Os materiais cerâmicos da indústria de cerâmica vermelha para ter uma longa vida útil depende da composição química da argila, da sua utilização correta durante a execução da obra, do ambiente em que a edificação foi construída, e para corrigir os efeitos das manifestações patológicas devem ser constantemente feitas a sua profilaxia. Foi possível perceber na edificação (estábulo) da vacaria da UECE (Universidade Estadual do Ceará) a deterioração dos blocos cerâmicos (seis furos) como também os tijolos maciços branco. O reboco devido a deterioração dos tijolos cerâmicos atacados pelo salitre (sal) existente na argila soltou, pois não tinha como continuar a aderência entre os blocos (tijolos furados de seis furos) e o reboco devido a própria deterioração dos tijolos de cerâmica vermelha na parede. A argamassa se soltou tanto na parte da parede feita de blocos de cerâmica vermelha como na parte feita de tijolos brancos, como também o pilar feito de tijolos brancos (Figura 6).

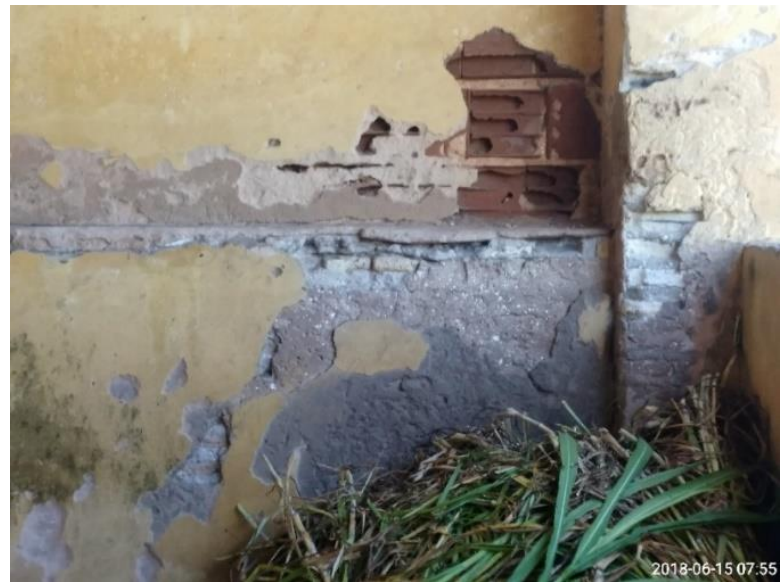

Figura 6 - Deterioração dos tijolos cerâmicos atacados pelo salitre (sal) existente na argila. Fonte: própia, 2018.

Foi possível perceber pelo telhado de um galpão da indústria de cerâmica vermelha coberto de telhas cerâmicas que temos dois tipos de telhas no galpão, onde na parte da direita do galpão que é bem antigo, as telhas já apresentam patologias como o escurecimento delas, devido a ação da chuva é dos ventos, enquanto do lado esquerdo do galpão foram colocadas telhas cerâmicas mais recentemente e elas permanece com a Manifestações Patológicas nos Produtos Cerâmicos Utilizados nas Obras de Construção Civil 
coloração avermelhada. O escurecimento decorre da alternância de umidade ocasionado pelas chuvas e períodos longos de seca como ocorre na região semiárida do nordeste brasileiro, acarretando assim o aparecimento de manchas escurecidas. $O$ galpão onde as telhas estão com manifestações patológicas apresentam uma cor preta e foi construído a cerca de 40 anos atrás. As telhas de cerâmica vermelha ficam pretas depois de muitos anos e para corrigir (profilaxia) a manifestação patológica devem ser utilizados os hidrofugantes. A manifestação patológica mais encontrada em telhas de cerâmica vermelha é o envelhecimento. A indústria de cerâmica vermelha já chegou a fabricar telhas, porém hoje só fabrica blocos cerâmicos de vedação e lajotas H8 utilizadas na confeç̧ão de lajes (Figura 7).

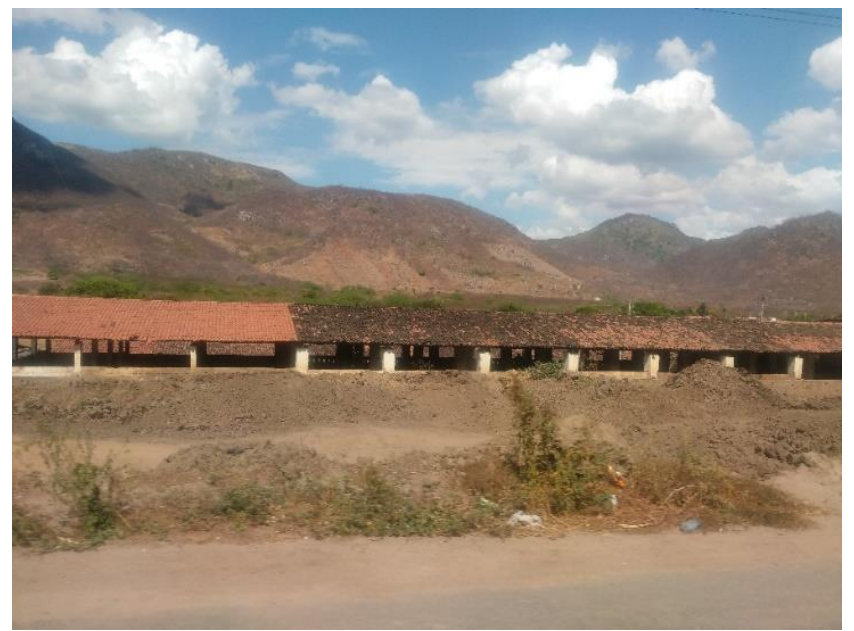

Figura 7 - Telhas cerâmicas com envelhecimento. Fonte: própia, 2013.

\section{Conclusão}

As manifestações patológicas nos tijolos (blocos cerâmicos), ladrilhos cerâmicos e telhas encontradas neste trabalho, foram a umidade, eflorescência, envelhecimento, manchas e degradação devido a presença de salitre na argila (matéria prima) que é utilizada para a fabricação dos materiais cerâmicos fabricados pela indústria de cerâmica vermelha.

Nos tijolos maciços e tijolos furados analisados, foi possível concluir que as manifestações patológicas nesses materiais cerâmicos da indústria de cerâmica vermelha dependem da composição química da argila.

Foi possível perceber que mesmo com tantos anos de uso os tijolos cerâmicos expostos a vista, não degradaram tanto, mostrando que os materiais cerâmicos da indústria de cerâmica vermelha resistem mais a incidência de manifestações patológicas no decorrer de sua vida útil em relação a quase todos os materiais utilizados hoje pela indústria da construção civil.

Os materiais cerâmicos (tijolos, telhas, combogós, tubos cerâmicos, ladrilhos etc.) possuem uma longa vida útil e ainda é muito utilizado na indústria da construção civil.

\section{Referências}

AECWEB, (2020). Problemas em telhados: entenda quais são e porque acontecem. Disponível em: <https://www.aecweb.com.br/revista/materias/problemas-em-telhados-entenda-quais-sao-e-por-queacontecem/13803>. Acesso em: 26 dez. 2020.

Flores, I., Brito, J. (2005). Patologia e reabilitação de construção em alvenaria de tijolo. Apontamentos da Cadeira de Reabilitação de Edificios. Instituto Superior Técnico. Lisboa. Disponível em: < file:///C:/Users/user/Downloads/Patologiaereabilitaodeconstruoemalvenariadetijolo.pdf>. Acesso em: 04 mar. 2021. 
Ferreira, C. C., Bergmann, C. P. (2011). Formação da eflorescência em cerâmica vermelha: fatores de influência no transporte dos íons $\mathrm{SO}_{4}{ }^{2-}$ e $\mathrm{Ca}^{2+}$. Cerâmica. 356. 57. pg 356-363.

Frazão, J. C. F. (2015). Patologias relacionadas às coberturas: estudo de caso em edificações unifamiliares de interesse social na cidade de Campo Mourão - PR. 2015. 53 f. Trabalho de Conclusão de Curso (Bacharelado em Engenharia Civil) - Universidade Tecnológica Federal do Paraná. Campo Mourão. Paraná. Brasil.

Gil, V. M. A. (2007). Prevención de patologias en fachadas de ladrillo a la vista. I Congreso Internacional de Cerámica Roja. Salvador.

Secco, G. R.,Tirello, R.A. (2018). Estudio de patologías en albañilería de ladrillos a la vista en la estación Franco da Rocha. $6^{\circ}$ Congreso de Patología y Reabilitación de Edificios. PATORREB. São Paulo. Brasil.

Silva, J.M., Abrantes, V. (2007). Patologia em paredes de alvenaria: causas e soluções. Seminário sobre Paredes de Alvenaria, P.B. Lourenço et al. (eds.). Disponível em: < http://www.hms.civil.uminho.pt/events/alvenaria_2007/065_084.pdf>. Acesso em: 04 mar. 2021.

UFC - Universidade Federal do Ceará. (2021). Casa de José de Alencar. Disponível em: <http://www.ufc.br/cultura-e-arte/equipamentos-culturais/2040-casa-de-jose-de-alencar >. Acesso em: 05 dez. 2021. 